\title{
Uma década de cartas dos povos indígenas ao Brasil: correspondências de 2011-2020
}

\author{
Suzane Lima Costa
}

\begin{abstract}
Resumo
As cartas que os indígenas escreveram para o Brasil nos últimos dez anos são uma tradução política e cultural da nossa história passada e presente. Uma tradução que apresenta quem são os indígenas que escrevem cartas, ao mesmo tempo em que pergunta quem é o Brasil destinatário de suas correspondências, colocando em evidência situações próprias da ética desses escritos: 1. A cultura do enfrentamento, da repetição e da coragem; 2. O endereçamento para alguém que não está lá e o gesto do envio como uma política; 3. A carta como gesto utópico e os sentidos do bem viver no Brasil. O modo como essas cartas são escritas e postadas, em diferentes redes sociais na Internet ou divulgadas em páginas de organizações nãogovernamentais, diz de um novo experimento cultural, político e literário, oferecido à sociedade brasileira pelos indígenas como uma ética para a vida que querem e precisam ter como povos originários. Pretendo tratar dessas situações, neste artigo, retomando trechos de cartas escritas pelos indígenas e enviadas para o Brasil no período de 2011-2020.
\end{abstract}

\begin{abstract}
The letters that the indigenous people wrote to Brazil in the last ten years are a political and cultural translation of our present history. A translation that presents who are indigenous who write letters, while asking who is the Brazil of their correspondences, highlighting situations specific to the ethics of these writings: 1 . The culture of confrontation, repetition, and courage; 2. Addressing someone who is not there and sending gestures as a policy; 3. The letter is a utopian gesture and the meaning of good living in Brazil. The way these letters are written and posted on different social networks on the Internet or published on the pages of non-governmental organizations tells of a new cultural, political and literary experiment, offered to Brazilian society by indigenous peoples as ethics for the life they want and need to have as original peoples. In this article, I intend to deal with these situations by resuming excerpts of letters written by indigenous peoples between 2011-2020 and sent to Brazil, under the name of presidents, governors, and other political authorities.
\end{abstract}




\section{Quem são os indígenas que escrevem cartas?}

Guarani Kaiowá, Xavante, Terena, Tikuna, Yanomami, Pataxó, Xucuru-Kariri, e uma lista de mais de 170 povos, há décadas escrevem cartas para o Brasil. Cartas para não morrer, cartas como gestos utópicos, como enfrentamento político, como pós-luta e luto. De 2011 a 2020, foram mais de 700 cartas escritas por indígenas, endereçadas e repetidas vezes enviadas ao estado brasileiro como ato político. Cartas sem respostas. Uma década sem respostas. Ainda assim, os envios continuaram. O que dizem essas cartas, esses gestos, sobre a década de um país? O que dizem essas cartas sobre os seus próprios remetentes? Quem deveria responder às cartas dos indígenas? Tratarei aqui dessas cartas como uma versão do Brasil pela voz dos indígenas: uma versão atualizada das guerras pelas terras dos indígenas e dos modos sofisticados de sua normalização e regulação; uma versão institucionalizada da violência contra os indígenas, dos seus modos políticos de viver/morrer enfrentando o Estado brasileiro.

Pretendo demonstrar como essas cartas são a própria utopia dos indígenas, porque ainda que a morte e a violência sejam partes protagonistas de suas composições, o gesto de escrever e o gesto de enviar essas correspondências nos apresentam a uma vontade e a uma crença em um outro modo de vida. Para tanto, tentarei conversar com as perguntas supracitadas, apresentando trechos e imagens de algumas das cartas para não morrer, das cartas-gestos e das cartas-instalações produzidas durante os anos de 2011 a 2020 e que compõem hoje o portal Cartas Indígenas ao Brasil. ${ }^{1}$ Defendendo a ideia de que são os próprios indígenas quem respondem às suas cartas e respondem com o gesto continuado de escrever, com suas lutas políticas, com suas artes.

Há uma linha temporal de cartas que narram o Brasil ao descrever as mortes violentas de líderes e de outros indígenas. Há uma linha e há também seus pontilhados e borrões, desvios da própria temporalidade da composição desses escritos que permitem traduzir política e culturalmente o Brasil passado e presente. Uma tradução que apresenta quem são

\footnotetext{
${ }^{1}$ Trata-se do primeiro arquivo digital de cartas escritas por indígenas e encaminhadas ao Brasil em três importantes períodos da nossa história literária e política: 1630-1680 (antes do Brasil), 1888-1930 (na nação Brasil) e entre 2000-2020 (no presente Brasil). Com a criação desse arquivo, analisamos as composições desse tipo de escrita, discutindo quem é o Brasil destinatário dessas cartas, tanto para apresentar os modos como diferentes líderes indígenas, ao biografar suas próprias vidas, narram uma outra história do Brasil, quanto para demonstrar como nessas correspondências os povos indígenas nos apresentam a uma outra concepção de autoria: a noção de povo-autor. Endereço do Portal: http://cartasindigenasaobrasil.com.br. Para mais informações acesse o blog: https://cartasindigenas.blogspot.com/ ou Instagram: https://www.instagram.com/cartas.indigenas/
} 
os indígenas que escrevem cartas, ao mesmo tempo em que pergunta quem é o Brasil destinatário de suas correspondências, colocando em evidência situações próprias do ethos desses escritos: 1. Uma cultura do enfrentamento, da repetição e da coragem; 2. Um endereçamento para alguém que não está lá e o gesto do envio como uma política; 3. A carta como gesto utópico e os sentidos do bem viver no Brasil.

\section{Cartas para não morrer}

Na última década, cerca de mil indígenas foram assassinados no Brasil em ações de disputa de terras. No último relatório divulgado pelo Conselho Indigenista Missionário (CIMI), só em 2015, 137 indígenas foram assassinados. Para a Secretaria Especial de Saúde Indígena (SESAI) é possível que esse número seja maior, porque nem todas as mortes são registradas ou denunciadas. Infelizmente, no Brasil, ser indígena já é condição para inúmeros crimes de mando. A morte por assassinato não é um assunto recente entre os indígenas. Com isso quero dizer que não foram os modos de matar "os índios" que ganharam novos arranjos políticos, mas foram os modos de narrar essas mortes que ganharam novas plasticidades nas vozes dos indígenas, que encontraram formas de reação e um outro modo de denunciar e perspectivar seu presente (Costa, 2018).

Veremos o que dizem essas narrativas em trechos de algumas cartas-denúncias escritas pelos próprios indígenas. Começo pelo ano de 2011. A carta de recepção à presidenta Dilma em 31 de janeiro de 2011, enviada pelos Guarani Kaiowá, antes mesmo da tão conhecida carta de suicídio coletivo em 2012, é emblemática não só dos assassinatos sofridos, mas da impossibilidade do luto entre os indígenas. Diz a carta:

Dourados, 31 de Janeiro de 2011.

Presidente Dilma,

Que bom que a senhora assumiu a presidência do Brasil. É a primeira mãe que assume essa responsabilidade e poder. Mas nós Guarani Kaiowá queremos lembrar que para nós a primeira mãe é a mãe terra, da qual fazemos parte e que nos sustentou há milhares de anos. Presidenta Dilma, roubaram nossa mãe. A maltrataram, sangraram suas veias, rasgaram sua pele, quebraram seus ossos. (...) Presidente Dilma, a questão das nossas terras já era para ter sido resolvida há décadas. Mas todos os governos lavaram as mãos e foram deixando a situação se agravar. Por último, o ex-presidente Lula prometeu, se comprometeu, mas não resolveu. Reconheceu que ficou com essa dívida para com nosso povo Guarani Kaiowá e passou a solução para suas mãos. E nós não podemos mais esperar. Não 
nos deixe sofrer e ficar chorando nossos mortos quase todos os dias. Não deixe que nossos filhos continuem enchendo as cadeias ou se suicidem por falta de esperança. (Grande Assembléia do povo Guarani Kaiowá- Aty Guasu, 2011)

Em outubro do ano seguinte, os 50 homens, 50 mulheres e 70 crianças das comunidades Guarani Kaiowá originárias do Tekoha Pyelito kue/Mbrakay pedem em carta que decretem a morte coletiva de todos eles e que os enterrem na sua terra ancestral:

(...) Pedimos, de uma vez por todas, para decretar a nossa dizimação e extinção total, além de enviar vários tratores para cavar um grande buraco para jogar e enterrar os nossos corpos. Esse é nosso pedido aos juízes federais. Já aguardamos esta decisão da Justiça Federal. Decretem a nossa morte coletiva Guarani e Kaiowá de Pyelito Kue/Mbarakay e enterrem-nos aqui. Visto que decidimos integralmente a não sairmos daqui com vida e nem mortos. Sabemos que não temos mais chance em sobreviver dignamente aqui em nosso território antigo, já sofremos muito e estamos todos massacrados e morrendo em ritmo acelerado. Sabemos que seremos expulsos daqui da margem do rio pela Justiça, porém não vamos sair da margem do rio. Como um povo nativo e indígena histórico, decidimos meramente em sermos mortos coletivamente aqui. Não temos outra opção esta é a nossa última decisão unânime diante do despacho da Justiça Federal de Navirai-MS. (GuaraniKaiowá, 2012)

Com o anúncio do que ficou conhecido como suicídio coletivo, os Guarani Kaiowá mais uma vez lembraram ao Brasil que o índice de suicídios entre indígenas é seis vezes maior do que a média nacional. Segundo dado da Secretaria Especial de Saúde Indígena (SESAI), entre 2004 e 2014, foram cerca de 500 casos. A carta dos Guarani Kaiowá foi a única correspondência que gerou manifestações em todo o país, principalmente nas redes sociais, cujos usuários passaram a agregar o nome Guarani Kaiowá ao seu perfil. ${ }^{2}$ Perspectivar o futuro é parte também da agonia dos mais jovens, que hoje têm no trabalho para os próprios fazendeiros e na mendicância seu modo de existência (Costa, 2018). Contudo, são os remetentes dessas correspondências líderes ativos que, desde o assassinato de Marçal de Souza, em 1983, se organizam para criar entradas políticas nos códigos do poder dos não-indígenas no Brasil, tanto com a aprendizagem da escrita da Língua Portuguesa, quanto com as muitas parcerias políticas nacionais e internacionais agenciadas com

\footnotetext{
2 Esta carta provocou uma mobilização nacional a favor dos direitos do povo Guarani Kaiowá. Artistas, antropólogos, professores, indigenistas e outros intelectuais no Brasil se manifestaram de diferentes maneiras em apoio à comunidade.
} 
antropólogos, pesquisadores e demais indigenistas defensores da causa indígena (Costa, 2018). A escrita de cartas é um exemplo dessas entradas políticas.

No mesmo ano da publicação da única carta escrita por indígenas que mobilizou o Brasil, os familiares de Aldo Silva Mota e as comunidades indígenas da região das Serras, Terra Indígena Raposa Serra do Sol, escrevem uma carta datada de 25 de maio, indignados com a absolvição dos acusados pelo assassinato do líder indígena no dia 02 de janeiro de 2003:

Terra Indígena Raposa do Serra do Sol, 25 de maio de 2012.

(...) Ficamos nos perguntando então, quem matou o ALDO? Não tem nenhuma outra suspeita! Os caminhos percorridos por ALDO e as testemunhas foram convincentes, não temos testemunha ocular da execução, porém testemunhos e o desenho do caminho percorrido por ele para chegar até a fazenda e não mais retornar. Somente o seu corpo foi encontrado no dia 09 de janeiro na área da fazenda, onde já haviam acontecido muitas ameaças, cujos vaqueiros na sede da fazenda estavam fortemente armados, com capacidade para executar qualquer uma pessoa sozinha. Presenciamos também durante o julgamento o preconceito contra os povos indígenas por terem reconquistado as suas terras, mesmo após uma luta de trinta anos, onde foram assassinadas 21 lideranças indígenas, 54 ameaças de morte, 51 tentativas de homicídios, 80 casas destruídas, 71 prisões ilegais, 05 roças queimadas e 05 cárceres privados. Do lado contrário, todos os nãoíndios receberam as indenizações por suas benfeitorias. (Terra Indígena Raposa Serra do Sol, 2012)

No ano seguinte, as estatísticas de mortes violentas de líderes indígenas aumentaram e a repetição dos pedidos pela vida passou pelo corpo das mulheres, que perderam seus filhos para o Brasil. A carta da Federação das Organizações Indígenas do Rio Negro ${ }^{3}$ sobre a situação dramática sofrida pela comunidade Hupd'äh de Tat Dëh (Taracuá Igarapé), no rio Tiquié, é uma amostra disso:

Rio Negro, 03 de fevereiro de 2013.

O choro das mães ecoa pelas aldeias Hup. ${ }^{4}$ É ensurdecedor. Os pais carregam suas filhas nos braços. O cemitério abre-se novamente. São mais duas crianças. Duas

\footnotetext{
${ }^{3}$ Carta também assinada pelo COLETIVO BUOPÉS - Mobilização em Defesa da Saúde Indígena.

4 Também conhecidos como Hupda, Hupd'äh, Maku ou Macu, sua população vive no Amazonas e na Colômbia, e fala uma língua da família Makú. Suas aldeias estão nas Terras Indígenas Alto Rio Negro, Médio
} 
meninas que vimos sorrir, falar e andar pelas casas. Começavam a conhecer o mundo, os rios, os caminhos da mata. Começavam a brincar. Receberam seus nomes ancestrais escolhidos cuidadosamente por seus avós. Suas almas, recém chegadas do Lago de Leite, foram protegidas contra todas as doenças causadas pelas gentes-peixe, pelo Trovão, pelas gentes-cobra. Infelizmente, não resistiram às "doenças dos brancos". A gripe e a diarreia, a falta de medicamentos e atendimento médico, a sempre "falta de combustível" e a discriminação étnica venceram mais uma vez. Todos se reúnem em torno dos pequenos corpos. Abrem a cova. E choram. Choram ao ver crescer o /Dö'däh höd/, o cemitério das crianças. Choram ao ver crescer sua tristeza e revolta. (Federação das Organizações Indígenas do Rio Negro, 2013)

Nessa mesma carta uma outra trágica linha do tempo se constrói com os números das crianças mortas, assassinadas pelas doenças dos brancos e pela ausência de políticas básicas de saúde para assistir a comunidade. Continua a carta:

Na calha do rio Tiquié, em 2008, quatro (04) crianças morreram de coqueluche na comunidade de Taracuá Igarapé. Em novembro de 2010, houve três (03) mortes de crianças Hupd'äh nessa mesma comunidade antes da chegada do resgate do DSEI. No mesmo período havia muitas crianças com gripe e diarreia numa comunidade localizada um pouco acima, Barreira Alta, sendo que um caso considerado gravíssimo era de pneumonia aguda, além do quadro associado de desnutrição. Resgate solicitado. Resgate não realizado. Em 2011, na Comunidade Hupd'äh de Fátima, uma criança de 2 anos de idade faleceu em consequência da diarreia, segundo o AIS local. Em janeiro de 2012, o AIS havia informado que desde julho de 2011 não havia visita da equipe de saúde em Fátima. Recentemente, em Taracuá Igarapé, em 16 de janeiro de 2013, recebemos a notícia de que mais duas crianças - de dois e um ano de idade - faleceram em decorrência de vômito e diarréia. Os Hupd'äh ainda informaram a existência de muitas crianças com virose. (Federação das Organizações Indígenas do Rio Negro, 2013)

Ainda no ano de 2013, outras mães escrevem para a Presidenta Dilma, relatando a morte de Oziel Gabriel e o risco de morte de outros indígenas Terena. Escrevem as mães Terena:

Nós, mães Indígenas Terena de Mato Grosso do Sul, parentes do indígena assassinado Oziel Gabriel e mães dos demais Guerreiros Terena, que neste momento histórico arriscam suas vidas nas retomadas de nossas terras, sentindose impotentes diante da gravidade da situação e temendo novas mortes entre nossos filhos (...) hoje estamos de luto pela vida de nosso filho Oziel e temerosas

Rio Negro I, Rio Téa e Rio Apapóris, na região amazônica 
por nós e todos os nossos outros filhos que neste momento cumprem seu dever como Guerreiros Terenas(...) (Mães Indígenas Terena, 2013)

E no final do ano de 2013, em 08 de dezembro, os mesmos Terena listam seus mortos em outra carta que denuncia e repudia o agronegócio no Brasil:

Nosso estado registra o maior índice de lideranças indígenas mortas em contexto de conflito fundiário. Na maioria dos casos, há envolvimento direto das ditas empresas de segurança privada (estas que os ruralistas pretendem financiar com o dinheiro do leilão) ou serviço de pistolagem ilegal. Citamos alguns de nossos mortos:

- Cacique Marcos Veron, 72 anos, assassinado em 13.01.2003 (Ação Penal no 2003.60.02.000374-2, 1a Vara Federal de Dourados, MS);

- Dorival Benites, 36 anos, assassinado em 26.06.2005 (Ação Penal no 2005.60.06.000984-3, 1a Vara Federal de Naviraí - MS);

- Dorvalino Rocha, 39 anos, assassinado em 24.12.2005 (Ação Penal no 2006.60.05.000152-9, 1ํo Vara Federal de Ponta Porã/MS);

- Xurite Lopes, 73 anos, assassinada em 09.01.2007 (2007.60.05.00157-1, na 1ํㅡara Federal de Ponta Porã/MS);

- Ortiz Lopes, 46 anos, assassinado em 08.07.2007 (Inquérito Policial nº. 046/2007 na Polícia Civil de Coronel Sapucaia - MS);

- Oswaldo Lopes, assassinado em 29.05.2009;

- Genivaldo Vera e Rolindo Vera, assassinados em 29.10.2009 (Inquérito Policial no . 181/2009. Polícia Federal de Naviraí);

- Teodoro Ricardo, assassinado em 27.09.2011;

- Nísio Gomes, assassinado em 18.11.2011 (Inquérito Policial no․ 0562/2011 PF/Ponta Porã).

- Oziel Gabriel, assassinado em 30/05/2013 - vítima da violência do estado. (Conselho do Povo Terena, 2013)

Oziel, chorado pelas mães Terena na carta anterior e símbolo das mães que perderam seus filhos para o Brasil, infelizmente, não foi o último da lista. Na mesma carta, os indígenas denunciaram a perseguição ao líder Terena e integrante do Conselho do Povo Terena:

Denunciamos o atentado de morte impetrado contra a liderança Paulino da aldeia Moreira. Paulino é liderança Terena e integrante do Conselho do Povo Terena. No dia que saiu decisão suspendendo o leilão, ele estava na Justiça Federal. No mesmo dia à noite, ele foi atacado em sua aldeia: homens encapuzados jogaram gasolina em Paulino. Ele conseguiu escapar, mas teve o seu carro incendiado. Hoje, dia 8 de 
dezembro, sua casa foi arrombada pelas pessoas que ainda querem dar cabo de sua vida. (Conselho do Povo Terena, 2013)

Também em 2013, e em todo o ano de 2014, os indígenas começam a escrever muitas cartas sobre Belo Monte, enviadas do Canteiro de obras de Belo Monte:

Vitória do Xingu, Pará, 29 de maio de 2013.

Vocês vão entrar para matar. E nós vamos ficar para morrer. Nós não vamos sair sem sermos ouvidos. $\mathrm{O}$ governo federal anunciou um massacre contra os povos indígenas, os 170 guerreiros, mulheres, crianças e lideranças e pajés que estão aqui. Esse massacre vai acontecer pelas mãos das polícias, da Funai e da Justiça.Vocês já mataram em Teles Pires e vão matar de novo quando for preciso para vocês. ${ }^{5}$ Vocês mataram porque nós somos contra barragens. Nós sabemos do que vocês são capazes de fazer. Vocês querem nos ver amansados e quietos, obedecendo a sua civilização sem fazer barulho. Mas nesse caso, nós sabemos que vocês preferem nos ver mortos porque nós estamos fazendo barulho. Ocupação do canteiro de obras de Belo Monte. (Ocupação Belo Monte, 2013)

O ano de 2015 foi um dos mais violentos para os povos no novo século: 137 assassinatos. Das 61 cartas que os indígenas encaminharam para o estado brasileiro, 10 tratavam de assassinatos por disputa de terras. E, mais uma vez, os Guarani e Kaiowa choram seus mortos.

Tekoha Guasu Guarani e Kaiowa, 24 de junho de 2015

É com profunda tristeza e pesar, mais uma vez comunicamos a todas as sociedades nacionais e internacionais os assassinatos de três crianças indígenas Guarani e Kaiowa pelos fazendeiros, um bebê recém-nascido e três crianças foram incendiadas, e os cadáveres ocultados pelos fazendeiros no Mato Grosso Sul. Nós povos Guarani e Kaiowá estamos chorando em LUTO. No dia 24 de junho de 2015, os fazendeiros incendiaram um bebêe 3 as crianças indígenas. Os fazendeiros já assassinaram dezenas de indígenas Guarani e Kaiowa. Desde 2000, os fazendeiros assassinaram os indígenas e passaram ocultar os cadáveres dos indígenas. (Grande Assembléia do povo Guarani - Aty Guasu, 2015)

${ }^{5}$ Referência ao assassinato de Adenilson Munduruku durante a Operação Eldorado, da Polícia Federal, na Aldeia Teles Pires, localizada na fronteira entre os estados do Pará e do Mato Grosso. 
Na mesma carta, uma outra sequência de denúncia se apresenta:

No dia 5 de dezembro de 2007, rezadora idosa, 70 anos, Xurite Lopes, avó da menina incendiada, foi assassinada a tiro queima roupa no tekoha Kurusu Amba, pelos fazendeiros. Esses mesmos fazendeiros da fazenda Madama, em 2007, já assassinaram a avó das crianças, em junho 2015 assassinaram as netinhas da Xurite Lopes. Os assassinos não são julgados pela justiç,a do Brasil.

De modo igual. No dia 29 de outubro de 2009, no tekoha Ypo'i, 60 as crianças, 20 idosos, 40 adultos foram atacadas a tiros e massacradas pelos fazendeiros. Os dois professores Genivaldo Vera e Rolindo Vera foram assassinados e cadáveres ocultados pelos fazendeiros. De forma simila, com mesma tática dos pistoleiros dos fazendeiros, no dia 18 de novembro de 2011, o cacique Nisio Gomes foi assassinado e cadáver ocultado pelos mesmos fazendeiros. (...) Assim esses mesmos fazendeiros e seus grupos atacaram e assassinaram os Guarani e Kaiowá: Samuel Martins, Marco Veron, Dorival Benites, Dorvalino Rocha, Rolindo Vera, Genivaldo Vera, Xurite Lopes, Nisio Gome..., 3 crianc,as... seguem a lista. (Grande Assembléia do povo Guarani - Aty Guasu, 2015)

No governo do Presidente Michel Temer, os anos de 2016 e 2017 somam 155 cartas, 21 delas sobre assassinatos e mortes violentas nas aldeias. Já os anos de 2018 e 2019, durante o governo do Presidente Jair Bolsonaro, foram escritas 170 cartas de povos e de associações indígenas, postadas nas redes sociais e em organizações não-governamentais indigenistas, 20 delas tratam dos assassinatos de indígenas que defendiam a demarcação de seus territórios, atuavam na proteção das divisas de suas terras ou combatiam a exploração madeireira e garimpeira. Para uma leitura do período, destaquei a carta do Povo Wajãpi, escrita pelo Conselho das Aldeias Wajãpi - Apina, esclarecendo as notas da Polícia Federal e do Ministério Público Federal, divulgadas no dia 16 de agosto de 2019, sobre a morte do cacique Emyra:

(...) Entendemos que o laudo da Polícia Técnica que concluiu que a causa da morte do chefe Emyra foi afogamento não significa que esta morte tenha sido por acidente, pois o laudo também confirma ferimentos na cabeça. Continuamos acreditando na versão da família do chefe de que a morte foi violenta, pois vimos as imagens do corpo onde aparecem marcas de pancadas na cabeça, cortes atrás da orelha e abaixo do olho e um furo no pênis que parece ter sido feito por uma faca. Estas imagens já foram entregues para a Polícia Federal, para a Funai e para a Comissão de Direitos Humanos da Câmara dos Deputados. Além disso, o corpo foi encontrado em um igarapé muito raso, onde é muito difícil uma pessoa adulta se afogar por acidente. Corrigindo a nota da Polícia Federal, informamos que a morte aconteceu perto da aldeia Waseity e que o corpo foi enterrado na aldeia Karapijuty(...) (Conselho das Aldeias Wajãpi - Apina, 2019) 
Em 2020, há 73 cartas no total e 11 sobre morte/assassinato. Algumas dessas cartas estão diretamente relacionadas às mortes pela Covid-19. A vida e as mortes dos indígenas no Brasil só confirmam a urgência de uma ação política que combata a cultura da violência contra indígenas, que sempre foi tratada com muita normalidade no Brasil. As cartas explicam os procedimentos dessa cultura, seus modos sofisticados de perpetuação, e nomeiam o Brasil como endereçamento responsável por uma normalizada política do "deixar morrer." O que mais impressiona nas cartas é que, no período de 2011 a 2020, não houve um ano sem o registro de uma morte violenta e sem narrativas de sujeições e desamparo. Também não houve, por parte do destinatário político das cartas - O Brasil executivo - uma resposta escrita formal ou informal aos indígenas.

Os coletivos, que assinam as cartas até então expostas aqui, trazem em suas palavras imagens repetidas das mortes violentas dos indígenas. Repetem essas imagens do mesmo modo que repetem o pedido de viver em sua terra, repetem para não morrer, repetem para manter o corpo alerta. Repetem como quem escreve em um transe ritualístico:

"Devolvam nossa Tekohá", "queremos morrer aqui", "nossos ancestrais foram enterrados aqui", "estamos sendo assassinados aqui". Repetir até tornar a repetição um tipo de ethos para viver ou morrer, ainda que sem respostas ou ainda que a resposta e a comoção dos outros só apareça quando os afetos de coragem viram gestos desesperados, quando todos os indígenas, homens, mulheres e crianças, decidem morrer. Mas o que acontece afinal quando uma repetição vira ethos? O medo diminui? Algum tipo de amparo é produzido? A produção de algum outro modo de agir é inventado? (Costa, 2018).

Acredito que sim, porque trata-se de um tipo de repetição no modo de escrever que, diferente do próprio ato de tornar a fazer, a dizer, não reitera as mesmas situações, as mesmas práticas, muito menos se trata de repetir como mero procedimento retórico ou como vício de linguagem.

Há um tipo de agir político na narrativa que repete à exaustão essas mortes e que faz da ausência do Estado democrático de direito a própria presença do Brasil nas cartas . Um gesto de escrever que ao se repetir insiste em manter uma conversa com o Brasil, algumas vezes nomeado, outras vezes sem nome nas correspondências. Desse modo, entre os anos de 2011 a 2020, o que temos, para além do expressivo número de correspondências enviadas para Presidentes, governadores e demais autoridades, é a repetição como uma ética: repetição dos nomes dos remetentes que assinam as cartas, repetição dos motivos que os fazem escrever, repetição das violências sofridas que denunciam nas cartas, repetição do 
desejo de justiça e a repetição dos modos não naturais de morrer, dentro de suas próprias casas.

Repetir à exaustão, repetir até tirar as palavras dos seus signos fixos, até criar outros fluxos que os retirem do luto, ou repetir até construir uma cultura da presença ativa do outro com quem se fala. Nas cartas indígenas, esse outro é o Brasil presente apenas pelo modo como é convocado como destinatário pelo sujeito da repetição. Explicar quem é o Brasil nas cartas dos indígenas é uma tarefa cheia de aporias e contradições, porque o Brasil é o para quem, destinatário específico da carta, e, ao mesmo tempo, o para qualquer um, aberto a escutar as palavras dos indígenas. Em outras palavras, o Brasil existe e não existe para os indígenas, tem nome próprio e rosto de ninguém nas cartas. Por outro lado, é possível dizer que falar do Brasil é nomear o sujeito da resposta, o sujeito da responsividade (Bakhthin, 2003), porque em suas cartas os indígenas escrevem para os Presidentes Dilma Rousseff, Michel Temer, Jair Bolsonaro, para o Brasil executivo, o Brasil que veta e chancela as políticas públicas em territórios indígenas. Assim, o Brasil nas cartas dos indígenas é o outro realidadeficção das suas diárias cenas políticas de enfrentamento, porque nem sempre tem seu nome exposto como sujeito da enunciação nas cartas, porém está sempre evocado como autor e partícipe do histórico cenário de guerra contra os povos originários.

A linha temporal das cartas apresentadas até então pode, de algum modo, criar um tempo cíclico para os indígena, no qual a repetição seja sempre posta não como diferença, mas como marco da derrota e dos modos de subalternização dos indígenas. Por isso, optei por ler o que chamei de pontilhados dessa linha, seus borrões, e por trazer também à superfície a ideia de que uma carta escrita pelos indígenas é também o gesto político e utópico do seu fazer. As cartas para não morrer são esses gestos, porque não foram lançadas ao Brasil apenas como forma de resistência, mas como uma maneira de dizer: "foi assim que aconteceu", "quem viveu fomos nós", "essa é a nossa narrativa e o nosso manifesto contra a cultura de violência", "nossa forma de enfrentamento", ou aquilo que Vladimir Safatle chamou de afeto de coragem (2015), que escancara o modelo falido de política que absurdamente é parte hoje da democracia brasileira.

Em outras palavras, essas cartas podem ser lidas como um modo que seus remetentes encontraram para cuidar de si mesmos, e o fato de as cartas serem continuamente escritas diz também da vontade de recusar uma leitura dos indígenas "a partir do paradigma de suas perdas culturais, étnicas e populacionais em constante conflito com seus colonizadores" (Santos, 2019, p. 190). Por isso, falar nos modos como os indígenas respondem ao seu destinatário, ou mesmo no modo como os indígenas não precisam da 
resposta do Brasil, apenas ativam o seu endereçamento para criar uma força de ação, é considerar que os indígenas "também construíram respostas ativas à dominação (...) frutos de um contexto específico, no qual identidades e experiências emergem de sujeitos que se reelaboram constantemente como protagonistas de suas histórias." (Santos, 2019, p. 190)

\section{As cartas-gestos de coragem}

Na mesma década das cartas para não morrer, uma série de outros modos de conversar com o Brasil foi criada por líderes e artistas indígenas: as cartas-instalações. Um modo de continuar escrevendo cartas para não morrer, instituindo na violenta segunda década do século XXI alguns efeitos contraculturais de coragem. Foi assim que o artista Macuxi Jaider Esbell escreveu uma carta-resposta ao velho mundo e ao capitalismo, uma carta que encontrou um modo de reação ao então Brasil de Bolsonaro. Na Carta dos povos indígenas ao capitalismo, performaticamente entregue a União dos Bancos Suíços, em 03 de abril de 2019, Jaider diz:

(...) Se não há futuro para nós, não haverá futuro para ninguém. Esse tempo presente é a última chance que temos para celebrar a vida, a vida com dignidade para todos; homens, animais, minerais, espíritos. Essa carta tem a intenção de convidar toda a humanidade para pensarmos juntos o futuro comum de nossas próximas gerações e isso é mesmo urgente. (Esbell, 2019)

Em 2020, esse futuro-presente, expresso pelo artista Makuxi também na Carta ao velho mundo (Esbell, 2020) ganhou as ruas do Brasil com a obra Entidades, a instalação que traduziu o que chamo de um gesto-carta e que tornou público outro encontro dos indígenas com os não-indígenas, a partir do quase beijo das cobras grandes abraçadas à imponência do tradicional viaduto Santa Tereza, em Minas Gerais. Diz a carta: 


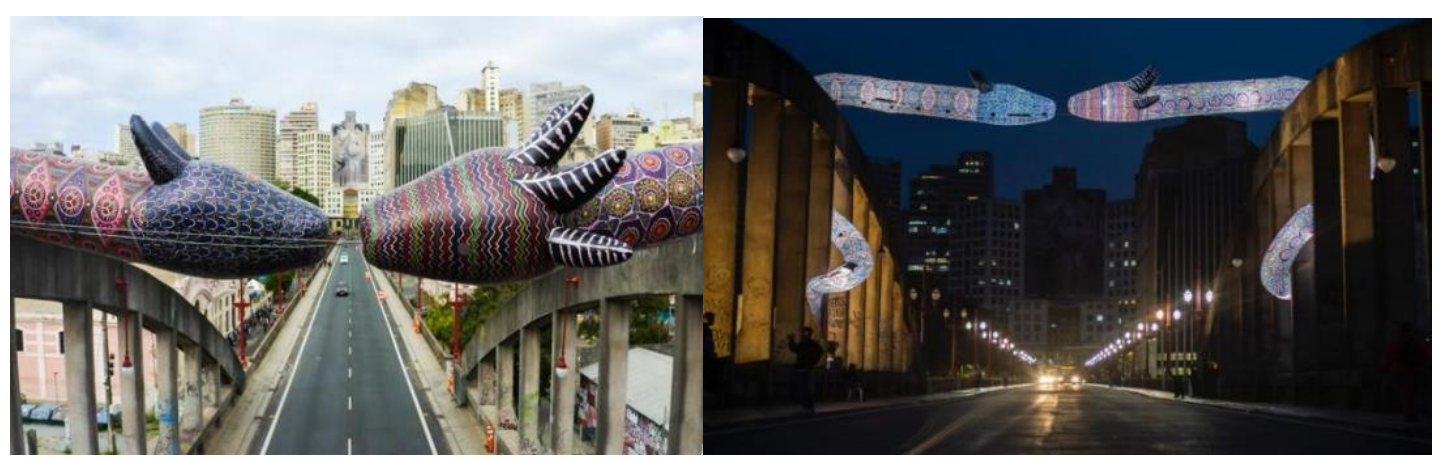

ENTIDADES, por Jaider Esbell (2020).

Fotos: Divulgação. 5. Edição do CURA, Circuito de Arte Urbana.

As cobras grandes que tentam conversar, como em um encontro entre remetente e destinatário, criam um efeito de partilha, a partir da composição de uma carta-instalação multicolorida e inflável, com 40 metros de comprimento, presa, ainda que movimentada pelo vento, à fixidez ferrosa da região central de uma grande capital brasileira. “Uma instalação que traduziu no quase encontro das duas cobras grandes uma correspondencia de 'bote' no peso da estrutura da cidade, no peso do velho discurso de "uma-só-naçãoBrasil" com seus projetos cafonas de progresso e desenvolvimento" (Costa, 2020, p. 208). No encontro, reatualizado por Jaider Esbell, do Brasil com o seu outro, as urgências de por em diálogo as pessoas das florestas e as dos condomínios, as cobras aquáticas e os carros elétricos. "Remetente e destinatário em uma outra ordem de presença e sentido". (Costa, 2020, p. 208)

As cartas-respostas do Esbell são um modo plástico de dizer o que as tantas cartas do Acampamento Terra Livre, as cartas da $\mathrm{APIB}^{6}$ e das tantas outras associações indígenas manifestam e denunciam há anos: como manter o direito à vida dos povos originários, $\mathrm{o}$ direito ao sonho e ao que os povos entendem como o seu bem viver. ${ }^{7}$ Há uma lista dessas denúncias descritas como sonhos em uma carta que Gersem Baniwa publicou no livro Cartas para o Bem Viver (2020). Repetindo a expressão "sonhamos um Brasil" em 12 excertos, Gersem mostra com qual destinatário-Brasil os líderes e as associações desejam conversar:

(...)Sonhamos um Brasil que compreenda, reconheça e respeite que nossa relação com o Estado está pautada pela orientação dos nossos direitos originários,

\footnotetext{
${ }^{6}$ Articulação dos Povos indígenas do Brasil.

${ }^{7}$ O Acampamento Terra Livre é o maior movimento dos povos indígenas no Brasil, realizado anualmente na cidade de Brasília, no mês de abril. Durante o evento, as lideranças indígenas de todo o país discutem formas de organização política, bem como apresentam suas demandas às autoridades públicas.
} 
amparados pelas nossas conquistas consagradas na Constituição brasileira e no Direito Internacional, como sujeitos e protagonistas de nossa história. Somos conscientes da dívida histórica que o Estado tem para com os nossos povos. Iremos lutar e permanecer em luta para que essa dívida seja reparada na concretização de nossos direitos, que a lei reconhece e determina que sejam garantidos (Baniwa, 2020, p. 34)

O Brasil dos indígenas, em utopias e distopias, está presente em mais 11 cartas dispostas na seção "O Bem Viver dos Indígenas". ${ }^{8}$ Duas dessas cartas foram criadas como imagens do que os artistas indígenas Arissana Pataxó e Denilson Baniwa defendem e antropofagizam como o Bem Viver. Na carta de Arissana, intitulada Pau-Brasil/2020, há a vontade de rasurar a história sangrenta do Brasil colonial no replantar pelas mãos indígenas - uma conversa com a terra, recorrente e principal tema das cartas indígenas e um modo de dizer que "os povos indígenas têm um papel importante não só na resistência, mas na construção da história do Brasil." (Santos, 2019, p. 269). Diz a carta:

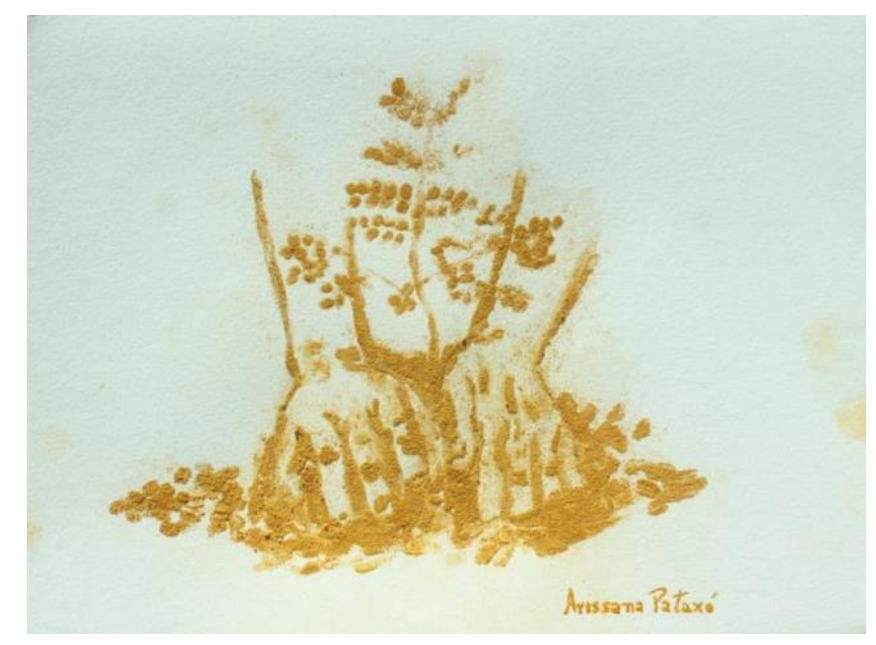

Pau-Brasil, 2020. Carta-imagem de Arissana Pataxó (2020)

Já a carta do Denilson Baniwa, presente na mesma seção de cartas do livro, "Reantropofagiza" (como ele mesmo costuma afirmar em suas ficções coloniais e em tantas outras artes) o conhecido quadro das equações ocidentais em códigos desenhados pelos

\footnotetext{
${ }^{8}$ Na seção estão também presentes as cartas de: Ailton Krenak, Sonia Guajajara, Juvenal Payayá, Graça Graúna, Márcia Kambeba, Rafael Xucuru-Kariri, Jerry Matalawê, José Carlos Tupinambá e Taquari Pataxó.
} 
Povos do Rio Negro. Nesse jogo com os códigos considerados universais, Denilson experimenta escrever para os parentes indígenas de Marte, para alertá-los sobre como seria para eles o processo de exploração e colonização que os indígenas sofreram aqui com a chegada dos europeus. De um modo jocoso e irônico, Denilson Baniwa adverte os seus parentes do outro mundo:

Niterói, Terra Indigena Karioka, 03 de outubro de 2020.

Ao Parente que vive na Terra Indígena Marte,

(...)Espero que você e seu povo não tenham que passar por tudo o que passamos aqui. Para isso, eu desenhei alguns códigos que servem como modelo e modo de pensar a vida e a caminhada do meu povo e, também, alguns desenhos que apresentam este planeta para você, caso, quando você venha nos visitar, não tenha mais o que temos hoje: florestas, rios, oxigênio, animais, vida (Baniwa, 2020, p. 53)

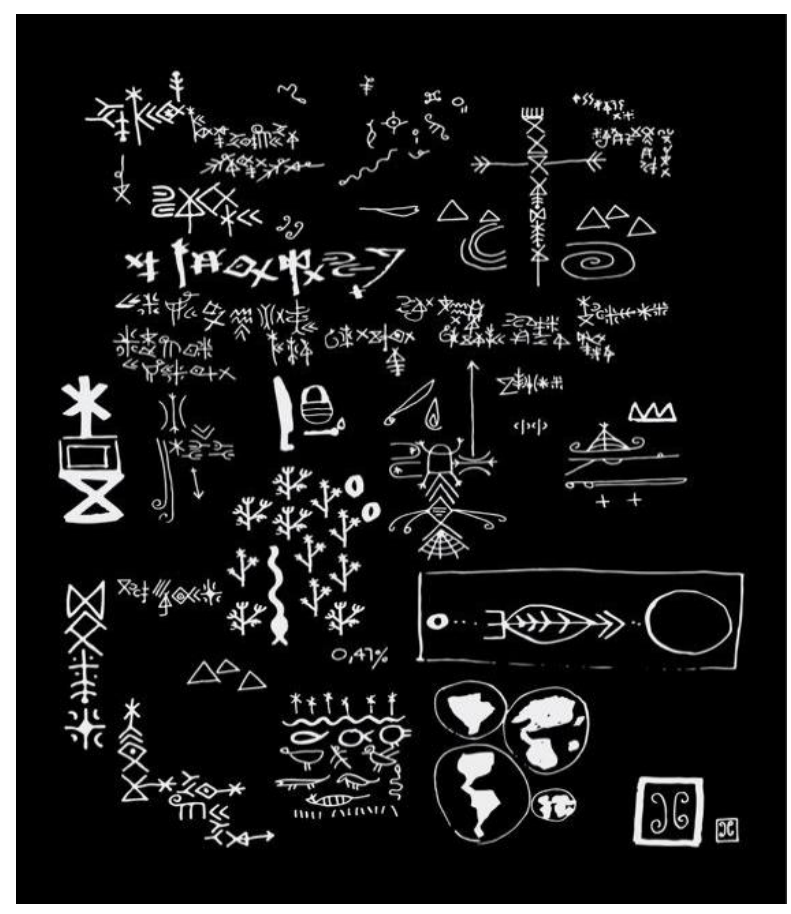

Carta aos indígenas de marte. Carta-imagem de Denilson Baniwa.

Da carta aos indígenas de Marte à imagem quase impossível de destinatário e remetente das cobras grandes, são essas cartas, que não se destinam ao Brasil, o seu avesso 
e a sua presença, a relação viva com o não lugar das suas políticas e, ao mesmo tempo, um modo ativo de dizer: sobrevivemos, apesar de tudo (Didi-Huberman, 2014).

Antes mesmo das cartas instalações do Denilson, da Arissana e do Jaider, antes mesmo do sonho do Gersem, em 2018, o circuito das cartas para não morrer foi atravessado pela carta da primeira indígena mulher candidata à vice-presidência do Brasil. Sonia Guajajara apresentou sua candidatura para os seus parentes e para os brasileiros, defendendo a importância de indígenas em cargos políticos de representação no Estado: defendendo um modo de tornar o corpo da exceção corpo instituinte e constituinte da própria cena política que o exclui.

(...) Quando nós resistimos e nos contrapomos a esse modelo, somos ameaçados, somos assassinados e até nossa voz querem silenciar. Nós não aceitamos isso. E quero aqui começar o ano falando sobre candidaturas indígenas em 2018. Diante de todos os ataques e retrocessos que vem perdurando durante toda a história, se faz necessário que nós indígenas com toda a nossa sabedoria, ancestralidade e articulação possamos nos adentrar nas candidaturas das próximas eleições para pleitear as vagas nos espaços institucionais ao Parlamento e ao Executivo, conforme for as nossas articulações políticos partidárias, e assim começarmos a ocupar esses espaços que até hoje, 518 anos depois, é ocupado em sua maioria por representantes muito distante ou totalmente contrário às causas populares e à diversidade desse país. (Guajajara, 2018)

Sonia Guajajara faz todos os trechos das cartas sobre os assassinatos de lideranças indígenas retornarem de um outro modo em sua escrita. O sujeito do desamparado escapa à repetição e passa a criar alternativas ao poder soberano. Os borrões na linha temporal das cartas para não morrer são expressos pela vontade de potência promovida pelos mesmos sujeitos que experimentam o desamparo em suas vidas (Safatle, 2015). Como as cartas da Sônia Guajajara, as demais cartas dos indígenas apresentadas aqui são um modo de escapar do circuito do medo no Brasil, de explicar seu funcionamento, isso porque só um circuito de afetos que não tenha o medo como fundamento pode garantir algum tipo de liberdade (Safatle, 2015).

Nesse sentido, as cartas para não morrer são cartas de coragem, que narram por si o que é a história política e cultural do Brasil - quando vivida pelo corpo dos indígenas. Essas cartas, decididamente, não tratam de uma história recente do Brasil, tratam sim de uma história do desde sempre da sua formação e invenção como nação. Uma história do ódio ao outro e da violência como fundação de repetidos, aflitivos e potentes afetos de coragem, por 
isso também uma história da força de muita gente que acredita e continua defendendo outros modos de vida. As cartas dos indígenas são o próprio Brasil, do passado às décadas mais recentes, porque são os nomes presentes/futuros das nossas urgências.

\section{Referências}

Bakhtin, M. (2003) Estética da criação verbal. 4.rd edn. São Paulo: Martins Fontes.

Baniwa, D. 'De Denilson Baniwa para o parente que vive na Terra Indígena Marte' in Costa, S. L. e Xucuru-Kariri, R. (eds.) Cartas para o Bem Viver. Livraria boto cor de rosa [online]. Disponível em:

http://www.livrariabotocorderosa.com/index.php/2021/04/20/cartas-para-o-bem-viver/ (Acesso em: 12 Maio 2021)

Baniwa, G. (2020) 'De Gersem Baniwa para as pessoas que sonham um outro Brasil' in Costa, S. L. e Xucuru-Kariri, R. (eds.) Cartas para o Bem Viver. Livraria boto cor de rosa [online]. Disponível em:

http://www.livrariabotocorderosa.com/index.php/2021/04/20/cartas-para-o-bem-viver/ (Acesso em: 12 Maio 2021)

CIMI (2015) Relatório Violência [Online]. Disponível em: https://www.cimi.org.br (Acesso em: 22 Fevereiro 2021)

Conselho das Aldeias Wajãpi - Apina (2019) Não significa que morte foi por acidente' diz conselho de índios sobre afogamento de Waiãpi [Online] Disponível em:

https:/g1.globo.com/ap/amapa/noticia/2019/08/20/nao-significa-que-morte-foi-poracidente-diz-conselho-de-indios-sobre-afogamento-de-waiapi.ghtml (Acesso em: 22 Dezembro 2019)

Conselho do Povo Terena (2013) Hánaiti Ho'únevo Têrenoe [Online] Disponível em: https://pib.socioambiental.org/es/Not\%C3\%ADcias?id=134476 (Acesso em: 20 Dezembro 2020)

Costa, S. L. (2018) 'As cartas das mulheres indígenas ao Brasil', Revista de Estudos Linguísticos e literários, 1(59), p109-123. Disponível em: https://periodicos.ufba.br/index.php/estudos/article/view/28856/17125 (Acesso em 28 Agosto 2020)

Costa, S. L. e Xucuru-Kariri, R. (eds.) (2020) Cartas para o Bem Viver. Livraria boto cor de rosa 
[online]. Disponível em:

http://www.livrariabotocorderosa.com/index.php/2021/04/20/cartas-para-o-bem-viver/ (Acesso em: 12 Maio 2021)

Deleuze, G. (1988) Diferença e repetição. Rio de Janeiro: Graal.

Didi-Huberman, G. (2014) Sobrevivência dos vaga-lumes. Belo Horizonte: Editora UFMG.

Esbell, J. (2019) Carta dos Povos Indígenas para o Capitalismo [Online]. Disponível em: http://www.jaideresbell.com.br/site/2019/04/03/carta-dos-povos-indigenas-para-ocapitalismo/ (Acesso em: 20 Maio 2020)

Esbell, J. (2020) Carta ao Velho Mundo [Online]. Disponível em: http://www.jaideresbell.com.br/site/2019/03/20/carta-ao-velho-mundo/ (Acesso em: 22 Abril 2021)

Esbell, J. (2020) Entidades [Online]. Disponível em: https://artebrasileiros.com.br/topo/curabh-2020/ (Acesso em: 22 Outubro 2020)

Federação das Organizações Indígenas do Rio Negro (2013). O choro das mães ecoa pelas aldeias Hup: é ensurdecedor. Carta aberta da Federação das Organizações Indígenas do Rio Negro [Online]. DIsponível em: https://cimi.org.br/2013/02/34416/ (Acesso em: 30 Agosto 2020)

Filho, C. M. (2001) 'Violência fundadora e violência reativa na cultura brasileira', São Paulo em Perspectiva, 15(2), p20-27. Disponível em:

https://www.scielo.br/scielo.php?script=sci arttext\&pid=S0102-88392001000200004

(Acesso em: 28 Agosto 2007)

Grande Assembléia do povo Guarani - Aty Guasu, 2015 (2010) Carta Kaiowá Guarani ao Presidente Lula [Online]. Disponível em:

https://www.ecodebate.com.br/2010/08/27/carta-kaiowa-guarani-ao-presidente-lula/ (Acesso em: 22 setembro 2010)

Grande Assembléia do povo Guarani - Aty Guasu, 2015 (2011) Carta Kaiowá Guarani à Presidente Dilma [Online]. Disponível em: https://www.brasildefato.com.br/node/5574/ (Acesso em: 22 setembro 2011)

Guajajara, S. (2018) Carta pré-candidatura à Presidência do Brasil [Online]. Disponível em: https://www.psol50.org.br/conheca-sonia-guajajara-primeira-indigena-em-uma-precandidatura-presidencial/ (Acesso em: 25 fevereiro 2018) 
Guarani Kaiowá (2012) Carta Guarani Kaiowá de Pyelito Kue/Mbarakay [Online]. Disponível em: http://goo.gl/GWZy21 (Acesso em: 20 outubro 2012)

Mães Indígenas Terena (2013) Carta das mães Terena à mãe da nação Dilma Roussef [Online]. Disponível em: http://odescortinardaamazonia.blogspot.com/2013/06/carta-das-maesterena-de-mato-grosso- do.html (Acesso em: 20 outubro 2013)

Ocupação Belo Monte (2013) Carta da ocupação Belo Monte do Povo Munduruku [Online] Disponível em: https://ocupacaobelomonte.wordpress.com/2013/05/29/carta-no-8-omassacre-foi-anunciado-e-so-o-governo-pode-evitar/. Acesso em: 10 set. 2016.

Pataxó, A. (2020) ‘Pau-Brasil' in Costa, S. L. e Xucuru-Kariri, R. (eds.) Cartas para o Bem Viver. Livraria boto cor de rosa [online]. Disponível em: http://www.livrariabotocorderosa.com/index.php/2021/04/20/cartas-para-o-bem-viver/ (Acesso em: 12 Maio 2021)

Safatle, V. (2015) Circuito dos Afetos: Corpos políticos, Desamparo, Fim do Indivíduo. São Paulo: Cosac Naify.

Santos, J. M. O. (2019) Ecos da liberdade: profetismo indígena e protagonismo Tupinambá na Bahia Quinhentista. Salvador: EDUFBA.

Terra Indígena Raposa Serra do Sol (2012) Carta sobre o caso Aldo da Silva Mota [Online]. Disponível em: https://racismoambiental.net.br/2016/06/24/caso-aldo-da-silva-motaapelacao-de-um-novo-julgamento-estara-em-pauta-no-tribunal-regional-federal-da-1aregiao-de-brasilia-no-proximo-dia-28-de-junho/ (Acesso em: 20 Abril 2021). 